\title{
Activity-Based Accounts of Mechanism and the Threat of Polygenic Effects
}

\author{
Johannes Persson
}

Received: 24 November 2008/Accepted: 28 September 2009/Published online: 22 October 2009

(C) The Author(s) 2009. This article is published with open access at Springerlink.com

\begin{abstract}
Accounts of ontic explanation have often been devised so as to provide an understanding of mechanism and of causation. Ontic accounts differ quite radically in their ontologies, and one of the latest additions to this tradition proposed by Peter Machamer, Lindley Darden and Carl Craver reintroduces the concept of activity. In this paper I ask whether this influential and activity-based account of mechanisms is viable as an ontic account. I focus on polygenic scenarios-scenarios in which the causal truths depend on more than one cause. The importance of polygenic causation was noticed early on by Mill (1893). It has since been shown to be a problem for both causal-law approaches to causation (Cartwright 1983) and accounts of causation cast in terms of capacities (Dupré 1993; Glennan 1997, pp. 605-626). However, whereas mechanistic accounts seem to be attractive precisely because they promise to handle complicated causal scenarios, polygenic causation needs to be examined more thoroughly in the emerging literature on activity-based mechanisms. The activity-based account proposed in Machamer et al. (2000, pp. 125 ) is problematic as an ontic account, I will argue. It seems necessary to ask, of any ontic account, how well it performs in causal situations where-at the explanandum level of mechanism - no activity occurs. In addition, it should be asked how well the activity-based account performs in situations where there are too few activities around to match the polygenic causal origin of the explanandum. The first situation presents an explanandum-problem and the second situation presents an explanans-problem-I will argue-both of which threaten activity-based frameworks.
\end{abstract}

\footnotetext{
J. Persson $(\bowtie)$

Department of Philosophy, Lund University, Kungshuset, Lundagård, 22222 Lund,

Sweden

e-mail: johannes.persson@fil.lu.se
} 
Mechanisms are entities and activities organized such that they are productive of regular changes from start or set-up to finish or termination conditions. (Machamer et al. 2000, p. 3)

\section{Mechanisms and Their Activities}

Together with his colleagues Lindley Darden and Carl Craver, Peter Machamer et al. (2000) has designed an influential framework for understanding mechanisms. Ontologically speaking, the framework is dualistic, postulating entities and activities as two kinds of ontological building block. These building blocks are organized in such a way that they are productive of regular changes in the mechanism's condition between onset and termination. It is particularly interesting that, in the relationship between activities and entities, activities are supposed to play the more important causal, and hence ontically explanatory, role:

Activities are the producers of change. Entities are the things that engage in activities. (Machamer et al. 2000, p. 3)

To mark the pronounced causal role of activities I shall refer to the framework as an activity-based account of mechanisms. This label is slightly misleading in one way, in that it conceals the dualistic nature of the account, but it is appropriate in the more important respect that it draws attention to what is new and different about the approach on offer. Machamer and colleagues often draw on examples from scientific research in molecular biology and neurobiology, ${ }^{1}$ but it is clear both from his original work and Machamer's further elaboration of the metaphysics of activities, that the intended application of the activity-based account is wider. The vast majority of the activities referred to in Machamer (2004) are not drawn from scientific settings. Examples include: running, bonding, flowing, the glass shattering and flying into a thousand pieces, breaking, boozing, covering up, and hiding.

\section{Ontic Explanations and Contextualization of the Argument}

Interest in causal mechanisms in the 1980s and onwards was intimately linked with the idea of ontic explanation. ${ }^{2}$

According to the ontic conception-as I see it, at least - an explanation of an event involves exhibiting that event as it is embedded in its causal network and/or displaying its internal causal structure. The causal network, external or internal, consists of causal processes transmitting causal influence and causal interactions in which the structures of the interacting processes are modified. (Salmon 1984, p. 298)

\footnotetext{
${ }^{1}$ Compare Tabery (2004).

2 The ontic conception, in turn, was inspired by certain previous perspectives on causal explanation (Salmon 1984, p. 293). For an early version of such an inspiring view, see Scriven (1971).
} 
Mechanisms and ontic explanations are still conceived in tandem. Machamer et al. (2000, sect. 3) emphasizes the ontic adequacy of conceptualizing mechanisms in terms of activities, ${ }^{3}$ and concludes by suggesting that "thinking about mechanisms gives a better way to think about one's ontic commitments" (Machamer et al. 2000, p. 23); Craver (2007, p. 27) explicitly adopts Salmon's conception of ontic explanation in his mechanistic account of neuroscience; and so on. Alleged scientific examples of ontic explanation abound in Salmon's texts and the mechanistic literature in general, but in several examples it remains a little unclear what an ontic explanation implies about the nature of the explanandum. ${ }^{4}$ For the purposes of this article I suggest the following partial but general characterization of the ontic conception.

On the ontic conception, explanations are relations between worldly existents. ${ }^{5}$ Ontic explanations may be partly or wholly cross-categorial in respect of the relata they relate (with mechanisms explaining regular changes, and so on), but this need not be the case (facts might explain facts, for example). The explanatory relation is often causal, but on a mechanistic view it may also be structural or "componential" (Craver 2007, p. 74). Which relation is at issue is assumed to depend on whether the explanation is aetiological or constitutive. Note that my stipulation is not motivated by the demand that, of the following two ways of putting the ontic conception, we should abandon the latter, statement-version:

It seems to me that either way of putting the ontic conception is acceptable; one can properly say that the explanandum-fact is explained by the explanansfacts or that the explanans-statements explain the explanandum-statement. (Salmon 1989, p. 86)

The statement-version is presumably compatible with the ontic conception via the truth-makers of the explanans- and explanandum-statements. The stipulation is merely intended to ensure that the explanandum-facts are supposed to be real worldly existents.

Machamer et al. (2000) contains little explicit talk about explanation. However, one thing it does say is that "explanation involves revealing the productive relation. It is the unwinding, bonding, and breaking that explain protein synthesis; it is the binding, bending, and opening that explain the activity of $\mathrm{Na}+$ channels. It is not the regularities that explain but the activities that sustain the regularities." This characterization clearly emphasizes the ontic elements by requiring a productive relation between explanans and explanandum. ${ }^{6}$ When this view is combined with

\footnotetext{
${ }^{3}$ Tabery (2004, p. 8) emphasizes this, too.

${ }^{4}$ Salmon's celebrated distinction between epistemic, ontic, and modal conceptions of explanation has been criticized of late. For one objection, see Strevens (2008, p. 11). It is not my purpose to add to the general evaluation. I am concerned only with ontic explanations.

${ }^{5}$ As far as I can see this reading was intended by (Coffa and) Salmon from the start: "Because of its emphasis on existent physical relationships, this view may be called the ontic conception of scientific explanation." (Salmon 1982/1998, p. 54)

${ }^{6}$ See Bogen (2005, p. 398) for a similar interpretation of Machamer's standpoint. Craver (2007, p. 28), on the other hand, places the account among views that think of explanation as explaining by subsuming a phenomenon under a general representation, prototype, or schema.
} 
the perspective on activities offered in Machamer (2004) it becomes a rather distinct mechanistic alternative that makes good sense of the idea of ontic explanations.

My focus on ontic explanations involving genuine activities has the consequence that the following discussion will be relevant only to certain mechanistic views; I am not seeking to attack mechanisms in general. Before we start it might be helpful to indicate in more detail what this article is not meant to be about. The observations I make will arguably prove irrelevant in the context of non-ontic mechanistic accounts. $^{7}$ My observations will also be irrelevant in the context of mechanistic accounts where activities play no, or at best a marginalized, role. ${ }^{8}$

Is the present problem relevant only in connection with Machamer's view, then? Not necessarily. It ought to bear to some extent on other ontic accounts of mechanisms conceived in terms of processes or activities. What about later developments of the view presented in Machamer et al. (2000), such as that adumbrated in Craver (2007)? Its other merits notwithstanding, the ontic standpoint in Craver (2007) is expressed in relatively unspecific terms, and this makes it more difficult to see what it is ontologically committed to with regard to the nature of the explananda. It seems to me that the priority of activities as the building blocks of mechanisms and explananda is downplayed. ${ }^{9}$

The activity-based account of mechanisms is, I submit, one of the more important developments in the mechanistic literature. It involves a distinctive take on what has been the core problem in philosophical reasoning about ontic explanation throughout the last couple of decades. That is why it will be the primary focus of this article. Its ontic aspects are clearly worthy of attention.

Before we proceed to the argument it should, perhaps, also be noted that I am not the first to identify and discuss problems with the activity-based account. For instance, Psillos (2004), Tabery (2004), and Campaner (2006) focus on the problematic concept of activity as well. However, none attacks the problem I am interested in. The rather fundamental problem with activities I explore here has not been addressed before-at least, to my knowledge. ${ }^{10}$

\footnotetext{
7 One, and a particularly clear, such account is given in Elster (2007). This characterizes mechanisms in a way that makes them depend on our epistemic condition.

8 There are an increasing number of such views, and I make no pretence of covering this field. Overviews of different phases of the mechanistic movement are provided in Psillos (2002), Tabery (2004), Campaner (2006) and elsewhere. However, a few examples will help to illustrate the kinds of view that are unlikely to be touched by the arguments of this article: the idea that the internal parts of mechanisms interact to the produce the system's external behavior set out in Glennan (1996); the modular perspective on the behavior of parts of mechanisms (with the parts conforming to generalizations that are invariant under interventions) set out in Woodward (2002); and the trope view of mechanisms set out in Persson (1997).

${ }^{9}$ Cf. the following passage from Craver (2007, p. 5, my emphasis): "This is a mechanism in the sense that it is a set of entities and activities organized such that they exibit the phenomenon to be explained." Moreover, explananda are not so clearly produced in Craver's account-in fact, part-whole relations between explanans and explananda seem more salient there (see Craver 2007, p. 139 and p. 165). These might be purely terminological changes on Craver's part, but since I am not sure I plan to stay strictly within the perspective offered by Machamer et al. (2000) and Machamer (2004).

${ }^{10}$ Psillos (2004, p. 314) also discusses the way in which activities struggle to explain causal interaction, but he focuses on another problem: "Note that it wouldn't help to try to explain the interaction between two parts of a mechanism (say parts A and B) by positing an intermediate part C. For then we would have to explain the interaction between parts $\mathrm{A}$ and $\mathrm{C}$ by positing another intermediate part $\mathrm{D}$ and so on (ad
} 


\section{What is an Activity?}

To examine the activity-based approach we need to identify some of its testable consequences. Below, I will describe one of these. It should be noted, however, that Machamer and his colleagues have not found it easy to provide a useful characterization of activities. They offer plenty of examples; and Machamer (2004, p. 29) gives quite a number of synonyms, or near-synonyms, of 'activities' as well: producings, happenings, ways of acting, processes and behaviors. However, nothing resembling a general account of activities has been provided. ${ }^{11}$

It should be clear that actualization is a central element of the concept of activity. In his work on Aristotle, Ross (1930, p. 82) says: "In each moment of activity, potentiality is completely canceled and transformed into actuality." There are no references to Aristotle in Machamer et al. (2000) or Machamer (2004) on this matter, but this characteristic of activities cannot have changed much. On the other hand, it is far from obvious that everyone interested in activities would be keen to postulate, or accommodate, potentiality in the world. In view of this, I would prefer to sidestep any potentially controversial issues raised by potentialities and actualities by claiming only that the following implication holds:

If entity $E$ engages in activity $\Phi$, then $E$ is $\Phi$-ing.

I will refer to this as the actualization claim. If the wheel (entity) engages in spinning (activity), then the wheel is spinning. If the heart (entity) engages in pumping blood (activity), the heart is pumping blood. This relationship relates activities to all of the near-synonyms listed above-to producings, happenings, ways of acting, processes, and behaviors; and it is unlikely to prompt any misgivings. Thus, the conditional above holds true for anyone who wants to deploy activities in the causal role attributed to them by Machamer and his colleagues.

We might add the following observation to the trivial one made above. There are two ways in which we might like to cash out $\Phi$-ing in the actualization claim. First, nobody engages in the activity of running unless someone is running (someone runs). It is not enough that there is merely an attempted running, or that there is the potential or a capacity to run. Second, the glass does not engage in the activity of shattering into a thousand pieces unless the thousand pieces actually result. It is not enough that the process begins if it is never completed-say, because the glass is caught before it hits the ground. Now let us compare these two cases.

The first case of $\Phi$-ing, running, is most naturally understood in terms of its intrinsic qualities. When there is a $\Phi$-ing of this sort, there is broadly speaking a

\footnotetext{
Footnote 10 continued

infinitum?)." Tabery (2004) argues that a complete account of mechanisms requires elements of both interactions and activities. Campaner (2006) criticizes the imprecise conception of activity deployed in activity-based accounts (and some other key concepts of alternative mechanistic perspectives as well). For (somewhat overlapping) explorations of the general problems of causation discussed in this article, see Dowe (2008), Hall (2004), Mellor (1995), Persson (1997; 2002), and Wolff (2007). However, none of these discussions explicitly concerns activities. Uskali Mäki's observation that mechanisms exist even when not operating is along the lines I am interested in, too, but there is a clear difference between us in that I am concerned here with operating mechanisms only.
}

11 See Tabery (2004) and Campaner (2006) for similar observations. 
process of a certain kind. If Peter, the entity, engages in the activity of running, Peter is running (Peter runs). This kind of case fits well with the idea that activities are usually designated by a verb or verb form-something which is noted in Machamer et al. (2000, p. 4), and which is reminiscent of Anscombe's (1981/1993) comparable view of causation a few decades earlier.

The second case of $\Phi$-ing, shattering into a thousand pieces, is more naturally understood in terms of the result or end-state of what happens. When there is a $\Phi$ ing of this sort there is an effect of a certain kind. If the glass, the entity, engages in the activity of shattering into a thousand pieces, there are a thousand pieces of glass (on my floor, for instance). This kind of case fits well with the idea that activities are constitutive of transformations that yield new states of affairs. ${ }^{12}$ I should perhaps emphasize here that I am not claiming that there are two distinct kinds of activity. Presumably every $\Phi$-ing has both an intrinsic quality and an effect-side. At least, this should be true of activities in mechanisms.

Indeed both characteristics seem to be highly relevant to a mechanistic project of the sort described above. Activities are supposed to provide a productive continuity between cause and effect, and accounting for this productive continuity is a major concern within the activity-based framework:

Productive continuities are what make the connection between stages intelligible. If a mechanism is represented schematically by $\mathrm{A} \rightarrow \mathrm{B} \rightarrow \mathrm{C}$, then the continuity lies in the arrows and their explication is in terms of the activities that the arrows represent. A missing arrow, namely, the inability to specify an activity, leaves an explanatory gap in the productive continuity of the mechanism. (Machamer et al. 2000, p. 3)

Looking at our two ways of conceiving activities, the intrinsic quality of $\Phi$-ing is central to the account because it ensures continuity. One factor driving the activitybased programme is a strong aversion to conceptions of change couched in terms of the mere possession of different properties at different times. This is made explicit in the particular programme I am taking as my starting point:

Mechanisms do things. They are active and so ought to be described in terms of the activities of their entities, not merely in terms of changes in their properties. (Machamer et al. 2000, p. 5)

... we might say that activities are ways of acting, processes, or behaviours; they are active rather than passive; dynamic rather than static. (Machamer 2004, p. 29)

However, while an activity provides continuity in virtue of the intrinsic qualities of $\Phi$-ing, it may nevertheless fail to produce the characteristic result or end-state. Therefore, the effect-element of activities is important too. Whether or not $\Phi$-ing is cashed out exclusively in terms of effects, ${ }^{13}$ the fact that activities in mechanisms are productive is important:

\footnotetext{
12 Compare Machamer et al. (2000, p. 4).

13 Activity as a functional kind is the strongest expression of this idea. It combines well with the teleological understanding of mechanisms one sometimes finds in the literature on activity-based mechanisms: Machamer et al. (2000), Machamer (2004, p. 36).
} 
Particularly, discovering activities, the 'doing' or productive parts of mechanisms, is the finding of causes. (Machamer 2004, p. 28)

Asked to defend an activity-based view of mechanisms, I would like to combine these two characteristics of activities so that the relevant activities of a mechanism were those involving both an intrinsic quality (a certain kind of process, broadly speaking) and an effect of $\Phi$-ing. Only in that way can it be guaranteed that a certain $\Phi$-ing provides not only continuity (process) or production (effect) but also a combination of these - that is to say, a productive continuity between the input and the output of the mechanism. This view, however, cannot easily be extracted from the writings of Machamer and colleagues. It is too implicit in what they say. Hence at this point I no longer claim to be following their example. Be that as it may, I now have the testable consequence I need.

\section{Polygenic Effects}

In their definition of mechanisms, Machamer and his colleagues speak about the organization of activities. Since activities are supposed to be closely related to causes, it is a small step from such talk to the idea of polygenic effects, i.e., effects that have more than one cause (or effects resulting from the organization of several activities). Prima facie many activities are such that it would be difficult to arrange them in a way that preserves the $\Phi$-ings, $\Psi$-ings and other actualizations that we have just concluded are necessary if some entity is to engage in a certain activity. In other words, activities seem to face a threat from polygeny. It is this threat that I examine in the remainder of the paper.

I begin with a simple example of polygeny: a motorboat heading east $(B)$ is suddenly affected by strong winds from the south, with the effect that the boat ends up northeast of its present position $(C)$. This effect is polygenic (Fig. 1).

It is natural to conceptualize this example, as Mill (1893, Bk. III, Ch. VI) did, in terms of forces: "a body is propelled in two directions by two forces, one tending to drive it to the north and the other to the east [...]." It is, moreover, tempting to follow Mill (ibid.) in his claim that, in this case, both forces have their full effect. The boat is "left precisely where it would have arrived if it had been acted upon first by one of the two forces, and afterwards by the other". Whether this is strictly true in real-life situations is another matter. Maybe the wind causes changes, such as waves in the environment around the boat, which make a difference to its capacity, or capacities, to move forward. But we do not need to consider such issues at this point.

\section{Two Kinds of Polygeny}

There is a common and in many ways unproblematic kind of polygeny: polygeny with respect to different properties of the effect or affected object. In many cases polygenic effects emerge precisely because the effect or affected object has many properties which the various causal contributors act upon. An apple, for instance, becomes ripe 


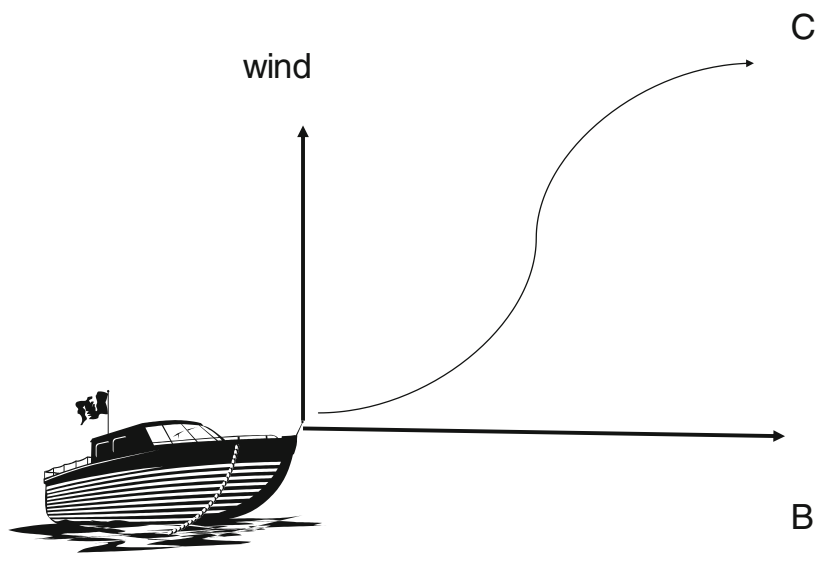

Fig. 1 Polygenic causation

and red at the same time, but ripening, we may assume, is a response to temperature, while reddening is a response to UV-exposure. Or, to recycle Hempel's (1970, pp. 421-423) example: the lava stream from the eruption of Vesuvius took a certain path; it had certain physical and chemical properties; and it occurred at a certain time that day in the year AD 79. Different combinations of causal contributor may have affected each of these properties. If the effect is the event, i.e., the eruption of Vesuvius, then this event is polygenic in virtue of the contributions to various properties of it. Therefore, polygeny is an especially common feature of theories positing events or other complex "thick" particulars (Armstrong 1978, p. 114) as causal relata.

The motorboat example, however, may be of a different polygenic kind. There the causal contributors act simultaneously, not only on different, but also on the same, property of the affected object. The forces exerted by the wind and the boat's engine both contribute to what are literally the same effects-some of which are represented by the boat's actual track from its starting position to $C$. $^{14}$

So, if we take the causal relata to be events or thick particulars with several properties or aspects, polygeny is a phenomenon that emerges in two ways. It emerges, first, when different causal contributors affect different properties of the particular; and, second, when there is a joint contribution to one of its properties. It might also occur where the causal relata are "atomic" facts, tropes or single aspects of particulars, but then only in the second way. I will assume that it is primarily the handling of polygeny of the second kind that might be problematic within the activity-based account of mechanisms.

\section{Activities and Polygeny}

The activity-based account of mechanisms makes a lot of sense. Accounts of mechanisms cast in terms of the activities their many parts are engaged in, and in

\footnotetext{
14 Both forces certainly contribute to other aspects, such as the speed of the boat, as well. This is because powers are often pleiotropic, i.e., such as to contribute to several effects. Compare Molnar (2003, p. 194).
} 
terms of the activities and regular changes that result from this, are useful in a number of ways. However, these accounts also have limitations, and one limitation becomes apparent when we look into two kinds of situation where more than one causal contributor is acting simultaneously. In the first situation of this sort, as a result of balancing causal contributors, nothing relevant happens, i.e., there is neither a relevant process nor a relevant effect that can constitute the actualization of an activity or a regular change at the relevant explanandum level. Hence there is nothing the activity-based mechanism can produce or explain ontically. In the second kind of situation there is, as a result of polygeny, a different kind of process and a different (kind of) effect than there would have been had the component activities been the explanans and the causal contributors.

The problems this limitation poses for activities I take to be the following: the first kind of case is undoubtedly causal and can be given an ontic explanation, but there is no causal production or componential constitution of the kind implied by the activity-based account. The right kind of explanandum is lacking. So the activitybased view has limitations as a causal and an ontically explanatory account. For those who are only interested in deploying mechanisms to describe or explain typical cases this might be of little consequence. However, for those who are looking for something more it might be reason to rethink the causal and ontically explanatory role attributed to activities. The second kind of case is not incompatible with the activity-based account as such, as far as causality goes, but that account has difficulty adequately accounting for it as a case of polygeny. The activity-based account seems to give at best a restricted, or partial, picture of the causal and explanatory complexity at issue. The right kinds of explanans are not available. On the plausible assumption that the second kind of case is frequent, this is, I think, at least as serious a problem as the first-although I would agree that the case I am presenting here is more tentative, partly because the activity-based account is currently difficult to interpret in some of its ontologically crucial aspects.

\section{The Explanandum-Problem and the Argument From Perfectly Balancing Causal Contributors}

Let us start with the first problem and have a look at our motorboat again. The wind, we can imagine, has now turned and comes directly from the east. Moreover, it perfectly balances the causal contribution made by the engine. The boat no longer has any speed or movement. Neither the boat nor the engine takes part in the forward-moving activity at all. At the relevant level of mechanism nothing happens. There is no relevant activity or regular change at the explanandum level (Fig. 2).

What we have here is an extreme form of polygeny - that is, one without activity at the level of mechanism in which we are interested. If change is a condition of effect here, this is a case of polygeny without effect. It can also be described in terms of the complete masking of the two capacities involved, or in terms of the perfect balancing of the two forces or causal contributors. Nevertheless, this situation is clearly causal. I have borrowed the first boat example from Wolff (2007); and in his terms, for instance, we still have a patient (the boat), which the 


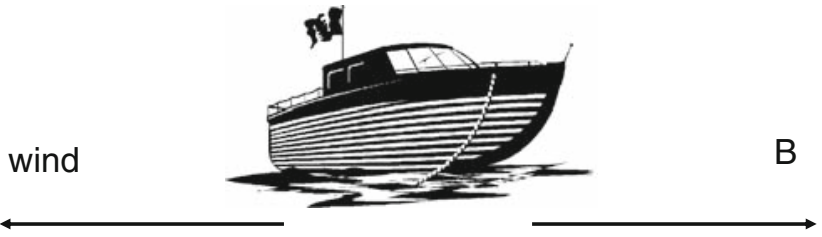

Fig. 2 Polygenic causation + no explanandum activity

affector (the wind) acts on, where the tendency of the patient $(B)$ is different from both the affector (the wind) and the actual end-state (status quo). The masking or balancing, like the outcome in typical cases of causation, is the result of many contributing forces, only in a slightly (but crucially) different kind of configuration than that in the first boat example.

Unlike many other polygenic effects, however, this extreme form of polygeny can occur only where two causal contributors act on the same property of the affected object. It is because the wind and the engine both contribute also to the same properties - the direction and speed of the boat - that the one capacity masks the other and the one force, or causal contributor, balances the other. Now, for the sake of this first argument it is enough to focus on the fact that this balancing has the result that nothing happens at the explanandum level of mechanism.

In order to claim this much one does not have to deny that there are activities in this situation on another level of the mechanism. This denial is superfluous even on the level where we identify the explanans in the first boat example (provided that explanans and explanandum belong to different levels of mechanism). ${ }^{15}$ There are activities inside the engine, and as a result its propeller takes part in one. But, as we should immediately concede, this is not something located at the explanandum level.

To recap: the main problem in this first counter-example is that no activity or regular change (at the explanandum level) is produced (or constituted) by what happens at the same or lower levels. For instance, even if the explanandum phenomenon can be characterized as maintaining constancy, ${ }^{16}$ this is something very different from the "regular changes" that should be "produced" on the activity-based account set out in Machamer et al. (2000). For the sake of the argument in this section I think we can happily accept that at a lower level the propeller is performing the same activity in both of our boat examples. The crucial difference is that it produces (aetiological version) or constitutes (constitutive version) an activity or regular change (at the relevant explanandum level) in the former example only. It is true that we might reinterpret the second static case as one in which the activities of the parts may be said to be non-productive ${ }^{17}$ of

\footnotetext{
15 However, if we have this problem on any given explanandum level it is likely to obtain on an explanans level as well (see discussion in next section). This observation strengthens the counter example but it is not required for the argument as such. That one of the alleged relata of the ontic explanation is lacking prevents the ontic relation from obtaining.

16 I am grateful to an anonymous reviewer for this suggestion.

17 As suggested by another anonymous reviewer.
} 
activities at the higher level; but on the assumptions that causation is always performed by activities and that ontic explanations always relate activities, this is not a viable response for the advocate of an ontically serious activity-based account of mechanisms. Causation and explananda suitable for mechanistic explanation are available in this case; the problem is that these are not of the right ontological kind for the activity-based account to handle.

We have identified at least one kind of situation where the activity-based account breaks down despite the fact that this situation is clearly causal and ontically explainable. It should now be easy to mimic this kind of extreme situation in connection with any other activities that lie at the heart of mechanistic interest: pushing/pulling, opening/closing, heating/cooling, attracting/repelling and binding/ releasing.

\section{The Explanans-Problem and the Argument From Different Effects and Processes}

The explanandum-problem of the previous section typically extends to an explanans-problem as well. This is for two reasons. The first reason is that ontic explanations of productive continuity are supposed to build chains-see, for instance the earlier quote from Machamer et al. (2000, p. 3): “A missing arrow, namely, the inability to specify an activity, leaves an explanatory gap in the productive continuity of the mechanism." ${ }^{18}$ Unless the local explanandum of interest coincides with the global explanandum of interest, what is explanandum in the local case is supposed to be (intermediary) explanans for some other phenomenon of interest. The second reason is simply that if there is no activity on the explanandum level this is often because the activities at the explanans level are counteracted. There is no activity at the explanandum level because there is no activity at the explanans level.

It is time to turn to the other, possibly much more widespread, kind of situation where advocates of activities might be threatened by polygeny. The assessment I offer in this section is both more general and more tentative than the one I provided in connection with the case discussed in the previous section. To be perfectly honest, I am not convinced that it presents a valid objection. I doubt whether at this point the activity-based approach has sufficient conceptual clarity to settle the issue. $^{19}$

In the cases to be considered here, the explanandum, $\Phi$-ing, that actually occurs is substantially different from the $\Psi$-ing that would have occurred if the entity had

\footnotetext{
18 See, also, the views on "bottoming out" in Machamer et al. (2000) and other writings.

19 On the other hand, this article is not the first to point to the kind of worry I raise in this section. Woodward (2002, pp. 372-373) expresses a related concern about how component activities are supposed to link with "overall productive relationships" on Machamer's view. Woodward's question is: if the overall (or higher-level) activity and the alleged component activity differ in kind, then how can the component activity be productive of the effects of the higher level activity? He thinks this question is problematic because we cannot assume that productivity is a transitive relation. As will be seen below, my problem is similar, but my reasoning is different.
} 
engaged in a certain explanans activity $\Psi$. In order to strengthen the argument for this I will offer two versions of it: one where the actualizations of the activities, i.e., the $\Phi$-ing and the $\Psi$-ing, are conceptualized strictly in terms of what they produce (i.e., as effects of the activity), and one where they are characterized by their intrinsic qualities (i.e., as kinds of process, broadly speaking). Since an element of both is arguably present in our preferred understanding of actualization-as was claimed in the earlier discussion on productive continuity - it is of value to learn that both accounts face similar problems.

Let us start with different actualizations understood in terms of their effects. Surprisingly, even our first motorboat example, in all its simplicity, might be a perfect example of how a polygenic explanandum effect cannot be accounted for in terms of more than one explanans activity. What is the alternative to understanding what actually goes on there as one activity? On the present understanding of actualizations, the only alternative is that the end-effect is a combination of two activities both of which occur. The situation reminds us of Nancy Cartwright's position on vector-addition of forces:

We add forces (or the numbers that represent forces) when we do calculations.

Nature does not 'add' forces. For the 'component' forces are not there, in any

but a metaphorical sense, to be added; and the laws that say they are must also

be given a metaphorical reading. (Cartwright 1983, p. 59)

The plausibility of Cartwright's view depends on the way we conceive forces. If we understand them as activities defined in terms of the effects they produce, Cartwright's position seems exactly right. It is simply not the case that an activity, $\Psi 1$, productive of the motorboat ending up in $A$ and another activity, $\Psi 2$, productive of it ending up in $B$ occur. There is but one causal track describing how the boat moves from its starting-point to position $C$, and it does not pass through $A$ or $B$. There is no real sense in which the effect, $\Phi$-ing, is the combination of the effects of $\Psi 1$-ing and $\Psi 2$-ing. Activities cannot account for this polygeny of effect if they are cast in terms of what they produce. (Moreover, in many cases the allegedly polygenic effect differs more dramatically from the aggregate effect of $\Psi 1$-ing and $\Psi 2$-ing. The effects of combined medication are a well-known case in point.)

Let us continue with the parallel problem that emerges from a characterization of the actualization of activities in terms of the intrinsic qualities of the processes of actualization. Suppose there is an intrinsic difference between being guided by the wind ( $\Psi 1$-ing) and being guided by the engine ( $\Psi 2-i n g)$. Then the actual process, $\Phi$-ing, resulting in the track from starting point to $C$ will be neither of these kinds of process. If for no other reason than that the actual process inherits elements from both $\Psi 1$-ing and $\Psi 2$-ing, $\Phi$-ing will be intrinsically different from both $\Psi 1$-ing and $\Psi 2$-ing. This may even be necessary if constitutive approaches are to come out ontic at all. In fact it is arguable that unless the explananda differ from the alleged explanans, there can be no ontic relation between them. However, this leaves us with the possibility that, in some cases, the $\Psi 1$-ing and $\Psi 2$-ing do not exist, or have no explanatory role to play. Only the activity at the explanandum level is actualized. 
There is merely a $\Phi$-ing. It is these possibilities that the argument in this section trades on.

Compare two, more dramatically different, activities for a more radical transformation: we cannot subtract very many of the intrinsic qualities of a closing process without changing the relevant $\Phi$-ing, and therefore the relevant activity, into something else. For instance, some combinations of simultaneous attempts to increase the amount of water flowing through a pipe (upstream) with closingattempts (downstream) cannot be represented in terms of their characteristic activities, since they counteract one another and result in other kinds of activity. On an even more mundane level, trying to think and listen at the same time often has the result, at least for me, that there is neither an activity of thinking nor an activity of listening, since another process takes place. This becomes even clearer in cases of the type deployed in the previous section, i.e., in cases where there is no explanandum activity at all. In some of those cases, the result will be that there can be no explanans activity either. I can certainly try to push when someone else is pulling, but the pushing and its effect have to occur to be a $\Phi$-ing, i.e., if the entity is to engage in the activity. Similarly with the extreme polygenic effects that can result from trying to open and close at the same time - to simultaneously heat and cool, attract and repel, bind and release, and so on. It would be fanciful to claim that both activities nevertheless occur. This cannot be because the corresponding actualizations, $\Psi 1$-ing and $\Psi 2$-ing, are absent. But then, if they do not occur, then, of course, the activities cannot be the two interacting causal contributors to the polygenic effect under investigation. Sometimes, at least, activities and polygeny do not match.

In truth it does not matter whether we focus on effects or intrinsic qualities when we characterize the $\Phi$-ing in the conditional 'if entity E engages in activity $\Phi$, then $\mathrm{E}$ is $\Phi$-ing'. For, potentially, there are plenty of polygenic cases where only one $\Phi$ ing occurs-a $\Phi$-ing, moreover, that does not correspond to any of the causal contributors involved. Accordingly, efforts to highlight effects or intrinsic qualities cannot prevent some of the explanatory power of the activity-based account of mechanisms from being lost. Full explanatory power is limited to environments where the mechanism is set up in the right way, i.e., so as to be free of the threat of damaging kinds of polygeny.

\section{Why Bother?}

Why should mechanistic philosophers care about polygeny? It might be complained that there is no compelling reason for a mechanistic theory to accommodate polygenic causation. However, that would be an unfortunate complaint for at least two reasons. First, theories that do not recognize polygeny cannot account for some important cases of causation. This is a high price to pay, since it seriously diminishes their value as theories of causation and ontic explanation. Secondly, and what is even more alarming, failure to recognize polygeny will limit a theory's usefulness qua theory of mechanism as well. This is because many important mechanisms are thought to be decomposable into intricate patterns of parts which 
are themselves mechanisms, and to be embedded in larger mechanisms. For instance, the mechanism of which the motorboat is a part might be decomposed into the finer mechanisms of the engine, propeller, and construction of the body, and embedded in a larger mechanism including the wind. If these are going to do anything other than act on separate aspects of effects-as in the first kind of polygeny we discussed - or serially — one after another-genuine polygeny of the second kind is required. Thus, the inability to accommodate polygeny is a serious shortcoming in a theory of mechanisms.

Just how serious is the threat to activity-based accounts of mechanisms posed by polygeny? That will depend and may vary, of course, on the specific ontologies of activity-based mechanisms. To answer such questions robustly one needs to engage more fully with the metaphysics of activities. Currently, these issues are not worked out in sufficient detail to give us anything like a final verdict. Even so, I would claim, problems of the first kind discussed in this article, i.e., those apparent in situations where no activity occurs on the relevant mechanistic level, show that the activity-based account of mechanisms proposed in Machamer et al. (2000) is not the one true account of mechanisms, causation, and ontic explanation.

Acknowledgments I want to thank two of Erkenntnis' anonymous referees for a number of constructive comments. Many thanks also to the research community-both resident and visiting — at the Center for Philosophy of Science, University of Pittsburgh; and especially to Peter Machamer, Nicholas Rescher, John Norton, Bradley Wilson, Fritz Allhoff, Demetris Portides, and Hernán Pringe. The discussion there provided the inspiration for this paper. Grants from The Swedish Research Council and from Erik PhilipSörensen's foundation made the writing of this paper possible.

Open Access This article is distributed under the terms of the Creative Commons Attribution Noncommercial License which permits any noncommercial use, distribution, and reproduction in any medium, provided the original author(s) and source are credited.

\section{References}

Anscombe, G. E. M. (1981/1993). Causality and determination. In E. Sosa \& M. Tooley (Eds.), Causation (pp. 88-104). Oxford: Oxford University Press. (Reprinted).

Armstrong, D. M. (1978). Nominalism and realism: Universals and scientific realism (Vol. 1). Cambridge: Cambridge University Press.

Bogen, J. (2005). Regularities and causality; generalizations and causal explanations. Studies in History and Philosophy of Biological and Biomedical Sciences, 36, 397-420.

Campaner, R. (2006). Mechanisms and counterfactuals: A different glimpse of the (secret?) connexion. Philosophica, 77, 15-44.

Cartwright, N. (1983). How the laws of physics lie. Oxford: Clarendon Press.

Craver, C. (2007). Explaining the brain. Oxford: Clarendon Press.

Dowe, P. (2008). Causal processes. In Zalta, E. (Ed.), The stanford encyclopedia of philosophy (Fall 2008 Edition), URL = http://plato.stanford.edu/archives/fall2008/entries/causation-process/.

Dupré, J. (1993). The disorder of things. Cambridge, MA: Harvard University Press.

Elster, J. (2007). Explaining social behavior. Cambridge: Cambridge University Press.

Glennan, S. (1996). Mechanisms and the nature of causation. Erkenntnis, 44, 49-71.

Glennan, S. (1997). Capacities, universality, and singularity. Philosophy of Science, 64(4), 605-626.

Hall, N. (2004). Two concepts of causation. In J. Collins, N. Hall, \& L. Paul (Eds.), Causation and counterfactuals (pp. 225-276). Cambridge, MA: MIT Press.

Hempel, C. G. (1970). Aspects of scientific explanation. Oxford: Glencoe. 
Machamer, P. (2004). Activities and causation: The metaphysics and epistemology of mechanisms. International Studies in the Philosophy of Science, 18(1), 27-39.

Machamer, P., Darden, L., \& Craver, C. (2000). Thinking about mechanisms. Philosophy of Science, $67(1), 1-25$.

Mellor, D. H. (1995). The facts of causation. London: Routledge.

Mill, J. S. (1893). A system of logic. London: Longmans, Green, \& Co.

Molnar, G. (2003). Powers. Oxford: Oxford University Press.

Persson, J. (1997). Causal facts. In Library of Theoria no 22. Stockholm: Thales.

Persson, J. (2002). Cause, effect, and fake causation. Synthese, 131, 128-143.

Psillos, S. (2002). Causation \& explanation. Montreal and Kingston: McGill-Queen's University Press.

Psillos, S. (2004). A glimpse of the secret connexion: Harmonizing mechanisms with counterfactuals. Perspectives on science, 12(3), 288-319.

Ross, W. D. (1930). Aristotle. London: Methuen \& Co Ltd.

Salmon, W. (1982/1998). Comets, pollens, and dreams. In Causality and explanation (pp. 50-67). New York: Oxford University Press (Reprinted).

Salmon, W. (1984). Scientific explanation: Three basic conceptions. In PSA: Proceedings of the biennial meeting of the philosophy of science association (Vol. 2, pp. 293-305). Symposia and Invited Papers.

Salmon, W. (1989). Four decades of scientific explanation. Pittsburgh: University of Pittsburgh Press.

Scriven, M. (1971). The logic of cause. Theory and Decision, 2, 49-66.

Strevens, M. (2008). Depth: An account of scientific explanation. Cambridge, MA: Harvard University Press.

Tabery, J. (2004). Synthesizing activities and interactions in the concept of a mechanism. Philosophy of Science, 71, 1-15.

Wolff, P. (2007). Representing causation. Journal of Experimental Psychology, 136(1), 82-111.

Woodward, J. (2002). What is a mechanism? A counterfactual account. Philosophy of Science, 69, 366-377. 